\title{
Low-dose Insulin Treatment Ameliorate Glucose Metabolism in Type 1 Diabetic Rats
}

\section{Athena Xin Hui $\mathrm{Ng}^{1 *}$, So Ha Ton ${ }^{1}$ and Khalid Abdul Kadir ${ }^{2}$}

${ }^{1}$ School of Science, Monash University, Malaysia

${ }^{2}$ School of Medicine and Health Sciences, Monash University, Malaysia

\begin{abstract}
Study background: Type 1 diabetes is an insulin-dependent diabetes mellitus (IDDM) because the body does not produce sufficient insulin for daily need. Persistent high glucose level in the blood circulation can stimulate the advanced glycation end products/receptor for AGEs (AGE/RAGE) pathway leading to diabetic complications. Currently, there is no preventive measure for IDMM with only treatment focusing on delaying the onset of diabetic complications. This study aimed to investigate how the different insulin regimens given affect the glycemic control and glucose metabolism in type 1 diabetes. The effects on the AGE/RAGE axis were determined as well.

Methods: Twenty-one male Sprague-Dawley rats were randomly assigned into three groups (Group A streptozotocin-induced diabetic rats given high-dose insulin [5-7U per day], Group B: streptozotocin-induced diabetic rats given low-dose insulin [0-3U per day], Group C: non-diabetic control). Throughout the eight-week treatment, the body weight, systolic blood pressure and non-fasting blood glucose concentration were monitored. After eight weeks of treatment, fasting blood glucose concentration, glycated haemoglobin $(\mathrm{HbA} 1 \mathrm{c})$, nuclear factor kappa $\mathrm{B}(\mathrm{NF}-\mathrm{kB})$, AGE level and RAGE expression were measured.

Results: High-dose insulin treatment impaired glucose metabolism. On the contrary, diabetic rats receiving lowdose insulin showed reduced glucose level and improved insulin sensitivity towards the end of experiment. HbA1c level was significantly lower in low-dose insulin treated rats while NF-kB level was significantly lower in high-dose insulin treated rats $(p \leq 0.05)$. There was no significant difference in AGE levels in all the groups $(p>0.05)$ and only the heart tissues from the low-dose insulin treated group showed significant down regulation of the RAGE gene expression $(p \leq 0.05)$
\end{abstract}

Conclusion: Low-dose insulin treatment was shown to be a better therapeutic intervention for type 1 diabetes.

Keywords: Glycated haemoglobin (HbA1c); Hyperinsulinemia; Nuclear factor kappa B (NF-kB); Glycemic control; Streptozotocininduced diabetes

\section{Introduction}

Diabetes mellitus is a global epidemic problem that causes public health crisis worldwide. In 2011, there were 366 million diabetic patients. This value is estimated to rise up to 522 million in 2030 [1]. In developed countries, this chronic disease is one of the leading causes of death and cardiovascular disease is the major cause of mortality in diabetic patients [2]. In Malaysia, the prevalence of diabetes among those 30 years old and above has increased from $8.3 \%$ to $14.9 \%$ to $20.8 \%$ in 1996, 2006 and 2011 respectively [3]. This is certainly an economic burden to the healthcare industries if the number continues to increase by leaps and bounds.

Diabetes mellitus is a group of metabolic diseases characterized by increased blood glucose levels (hyperglycemia). This abnormal elevation of blood glucose occurs due to defects in insulin secretion, insulin action or both [4]. There are different types of diabetes based on the aetiology and clinical stages. The four main categories identified up to date are type 1 diabetes, type 2 diabetes, gestational diabetes and other specific types [5]. Type 1 diabetes is also known as insulin-dependent diabetes mellitus (IDDM) because the body does not produce sufficient insulin for daily need and thus regular insulin injections are required [4]. Currently, there is no preventive measure for IDMM with only treatment focusing on delaying the onset of diabetic complications. Insulin therapy is a common treatment for IDMM. Although insulin dosage should be individualized, designing an ideal insulin regimen for reference are undoubtedly of utmost interest.
Advanced glycation end products (AGEs) are the stable products of glycation after the amino group of protein, lipid or deoxyribonucleic acid (DNA) is reduced by sugar. Hence, glucose is a main precursor for the formation of AGEs [6]. AGEs accumulation inside the body is thought to play a role in the pathophysiology of several diseases particularly those related to diabetes [7]. Besides modifying the intracellular proteins, AGEs can form specific interaction with certain receptors that eventually exert detrimental effect on the cellular system $[8,9]$. To date, there are several AGE receptors identified and among these, RAGE is the most extensively studied. AGE-RAGE interaction is the key event that brings about the deleterious effects in tissues. RAGE is a multi-ligand transmembrane receptor of the immunoglobulin superfamily [10]. Nuclear factor kappa B $(\mathrm{NF}-\kappa \mathrm{B})$ is a transcription factor that binds onto the promoter region of RAGE to mediate inflammatory responses. Many vascular complications of diabetes have been implicated in the AGE-RAGE downstream signalling with the activation of NF- $\mathrm{KB}$ [11]. This study aimed to investigate how the

*Corresponding author: Athena $\mathrm{Ng}$ Xin Hui, School of Science, Monash University Malaysia, Jalan Lagoon Selatan, Bandar Sunway, 47500 Subang Jaya, Selangor, Malaysia, Tel: +60126332112; E-mail: axng1@student.monash.edu

Received December 23, 2015; Accepted January 07, 2016; Published January 19,2016

Citation: Ng AXH, Ton SH, Kadir KA (2016) Low-dose Insulin Treatment Ameliorate Glucose Metabolism in Type 1 Diabetic Rats. J Diabetes Metab 7: 635. doi:10.4172/2155-6156.1000635

Copyright: $\odot 2016 \mathrm{Ng} \mathrm{AXH}$, et al. This is an open-access article distributed unde the terms of the Creative Commons Attribution License, which permits unrestricted use, distribution, and reproduction in any medium, provided the original author and source are credited. 
different insulin regimens given affect the glycemic control and glucose metabolism in type 1 diabetes. Apart from that, it is crucial to know the effects on the AGE/RAGE axis as a primitive mean to ameliorate diabetic complications associated with type 1 diabetes.

\section{Materials and Methods}

\section{Animal ethics and treatments}

The procedure in using and handling animals in this research project had been approved by the Monash University School of Biomedical Sciences Animal Ethics Committee (AEC Approval Number: MARP/2013/082) in compliance to 2004 National Health and Medical Research Council (NHMRC) Australian Code of Practice for the Care and Use of Animals for Scientific Purposes ( $7^{\text {th }}$ edition) along with Victorian legislations and Monash University policies, procedures and guidelines.

Twenty-one male Sprague-Dawley rats (Rattus norvegicus) with initial weights ranging from $180 \mathrm{~g}$ to $240 \mathrm{~g}$ were housed individually in plastic cage at room temperature of $23 \pm 1^{\circ} \mathrm{C}$ and subjected to $12: 12$ hours light:dark cycle. Paper was used as bedding and was changed regularly to provide a hygienic environment. Prior to treatments, the rats were acclimatized for one week with ad libitum feeding with standard rat chow (Gold Coin, Malaysia) and tap water. After that, the rats were randomly divided into three Groups, A, B and C with each group comprising of seven rats.

The rats from Groups $\mathrm{A}$ and $\mathrm{B}$ were given $55 \mathrm{mg} / \mathrm{kg}$ of streptozotocin (Sigma, USA) via intraperitoneal injection to induce diabetes. A $30 \mathrm{mg} / \mathrm{mL}$ streptozotocin stock was prepared by dissolving $30 \mathrm{mg}$ of streptozotocin in $1 \mathrm{~mL}$ of $0.09 \mathrm{M}$ citrate buffer solution, $\mathrm{pH} 4.5$ (Sigma, USA). Rats from Group C were non-diabetic control. The rats were left for 10 days without any treatment to stabilize their conditions. After 10 days, the rats from Group A were given high-dose insulin (total 5-7 U/day) (NovoMix ${ }^{\circledR} 30$ Flex Pen, Denmark) with three times injection per day (at 0830, 1430, and 2130). On the other hand, rats from Group B were given low-dose insulin (total 0-3 U/day) with only one time injection per day (at 0830). No insulin treatment was given to the rats in Group C. All the rats were fed with normal diet consisting of standard rat chow and tap water. The duration of treatment was 8 weeks. Throughout the 8 weeks, the weight, systolic blood pressure and blood glucose concentrations were monitored.

\section{Measurement of blood pressure}

The blood pressure of rats were measured once every week using the MRBP Mouse and Rat Tail Cuff Method Blood Pressure System (IITC Life Sciences, USA). The tail cuff with pulse transducer was applied onto the tail of the rat placed in a plastic restrainer. The systolic blood pressures were measured once the rat had calm down (e.g. no vigorous agitation).

\section{Sample collection}

At the end of treatment, the rats were fasted for 12 hours prior to humane sacrifice. The rats were anaesthetized with a mixture of 75 $\mathrm{mg} / \mathrm{kg}$ ketamine and $10 \mathrm{mg} / \mathrm{kg}$ xylazine via intraperitoneal injection. Whole blood, serum and red blood cell lysate were collected. The serum and red blood cell lysate were stored at $-80^{\circ} \mathrm{C}$ until required for analysis. Various target tissues were harvested which included the liver (L), kidney (K), heart $(\mathrm{H})$, abdominal muscle (AM), subcutaneous adipose tissue (SAT) and visceral adipose tissue (VAT). Extracted tissues were collected in individual microcentrifuge tubes and snap frozen using liquid nitrogen. These tubes were then stored at $-80^{\circ} \mathrm{C}$ for further analysis.

\section{Blood and serum biochemical analyses}

The non-fasting and fasting blood glucose of rats were determined using Accu-Chek Performa glucometer (Roche, Switzerland). The HbAlc levels of the rats were determined using Rat glycated haemoglobin A1c (GHbA1c) ELISA Kit (Cusabio ${ }^{\circledR}$, China) while the serum NF- $\kappa B$ of rats was measured using Rat Nuclear Factor-kappa $B$ (NF- $\mathrm{kB})$ ELISA Kit (Cusabio ${ }^{\circledR}$, China). The serum AGE level of each of the rat was determined using OxiSelect ${ }^{\mathrm{TM}}$ Advanced Glycation End Product (AGE) ELISA Kit (Cell Biolabs, USA).

\section{Tissue total RNA extraction and cDNA synthesis}

The total RNA in the liver (L), kidney (K), heart $(\mathrm{H})$ and abdominal muscle (AM) were extracted using Qiagen RNeasy Mini Kit (Qiagen, USA) while the RNA of subcutaneous adipose tissue (SAT) and visceral adipose tissue (VAT) were isolated using Qiagen RNeasy Lipid Tissue Mini Kit (Qiagen, USA). The purity of the extracted RNA was assessed using a nanodrop program in the Infinite ${ }^{\circledR} 200$ PRO (TECAN, Switzerland) by determining the ratio of absorbance at $260 \mathrm{~nm}$ to $280 \mathrm{~nm}$. Agarose gel electrophoresis was carried out to assess the RNA integrity by examining the presence of $28 \mathrm{~S}$ and $18 \mathrm{~S}$ ribosomal bands. RNA extract was treated with RNase-free DNase using Fermentas DNase I, RNAse-free (Fermentas, Canada) to remove contaminating DNA. The prepared RNA was used as a template for reverse transcriptase in cDNA synthesis. The process was carried out using the Qiagen Omniscript Reverse Transcription kit (Qiagen, USA).

\section{Quantitative Reverse Transcription Polymerase Chain Reaction (qRT-PCR) of RAGE}

The qRT-PCR was performed using Rotor-Gene Q (Qiagen, USA). The gene to be studied was RAGE while the endogenous control was $\beta$-actin gene (BAC). The products of qRT-PCR were confirmed by running agarose gel electrophoresis. The nucleotide sequences of primers and probes used are listed in Table 1.

\section{Statistical analysis}

All data recorded were processed and analysed using Statistical Package for the Social Sciences (SPSS) version 22.0 with the exception of the relative expression of RAGE that was analysed using the Relative Expression Software Tool for Rotor-Gene 3000 and 6000 (REST-RG ${ }^{\odot}$ ) Version 3. Analysis of Variance (one way ANOVA) was used to analyse the data with parametric distribution. This was then followed by Post Hoc (Tukey) test when the results were significant. For non-parametric distribution data, Kruskal-Wallis test was used and when the results were significant, Mann Whitney U-test was carried out. Mixed Model ANOVA was used to analyse the weight, systolic blood pressure and non-fasting blood glucose. The relative expression of RAGE was evaluated based on the take-off points and PCR reaction efficiencies of the samples as analysed by the 'Comparative Quantitation' features of

\begin{tabular}{|c|c|}
\hline Primer/Probe & Nucleotide sequence (5' -->3') $^{\prime}$ \\
\hline BAC forward primer & GTA TGG GTC AGA AGG ACT CC \\
\hline BAC reverse primer & GTT CAA TGG GGT ACT TCA GG \\
\hline BAC probe & [TET] CCT CTC TTG CTC TGG GC [BHQ1] \\
\hline RAGE forward primer & CCT TGA CCT GTG CCA TCT CT \\
\hline RAGE reverse primer & GGG TGT GCC ATC TTT TAT CCA \\
\hline RAGE probe & [6FAM] CCC AGC CTC CCC CTC AAA TCC A [BHQ1] \\
\hline
\end{tabular}

Table 1: Nucleotide sequences of primers and probes for BAC and RAGE. 
Rotor-Gene Q and interpreted by REST-RG ${ }^{\odot}$ Version 3. This involved the calculation of the expression ratios of target to calibrator. In all the analyses, a $\mathrm{p}$-value of $\leq 0.05$ was considered statistically significant.

\section{Results}

The initial weight $( \pm$ SEM) of rats from Groups A, B and C were not significantly different until week 5 ( $\mathrm{p}>0.05)$. Starting from week 6 onward, rats in Group B showed a significantly slower weight gain $(\mathrm{p} \leq$ $0.05)$ compared to rats in Group A. The final body weight of rats from Group B was significantly lower than rats from group A $(p \leq 0.05)$. Rats in Group B also had the lowest weight gain. Rats in Groups A and $\mathrm{C}$ did not show any significant difference in body weight during the treatment period (Figure 1).

The initial mean systolic blood pressure $( \pm$ SEM) of rats from Groups A, B and C were not significantly different until week 3 ( $p>0.05$ ). Starting from week 4 to 6, rats in Group B and C started to show a difference in blood pressure. Rats in Groups A and B also showed significant difference in systolic blood pressure at week 5 (Figure 2). From the results, high- dose insulin treatment sustained the systolic blood pressure of the diabetic rats at a level similar to nondiabetic control rats.
In the early phase of the experiment (first five weeks), the rats in Group A (high-dose insulin treatment) achieved significantly lower mean blood glucose level as compared to Group B (low-dose insulin treatment) ( $\mathrm{p} \leq 0.001)$. Progressing towards the late phase of the experiment (week 6 to 8), the mean blood glucose level of rats in Group A started to increase. In contrast, the rats in Group B started to show a decrease in blood glucose level. At week 7, rats from both Groups A and B showed no significant difference in their mean blood glucose level ( $p>0.05)$. At week 8 , the mean blood glucose of the rats in Group A $(16.24 \pm 1.62 \mathrm{mmol} / \mathrm{L})$ was significantly higher than Group B $(10.36 \pm 0.75 \mathrm{mmol} / \mathrm{L})$. The mean blood glucose of rats in Group C remained significantly lower than both Groups A and B throughout the experiment $(\mathrm{p} \leq 0.001)$. The mean blood glucose was constant throughout the 8 weeks in Group C (Figure 3). For fasting blood glucose, the mean blood glucose concentration of the rats in Group B was significantly lower than Group A $(p \leq 0.05)$ at the end of the eight-week treatment. Concurrently, the mean fasting blood glucose concentration of rats in Group C was significantly lower than Group A as well $(\mathrm{p} \leq 0.05)$ (Table 2).

At the end of the eight-week treatment, the mean HbAlc concentration of rats in Group B was significantly lower than Group C

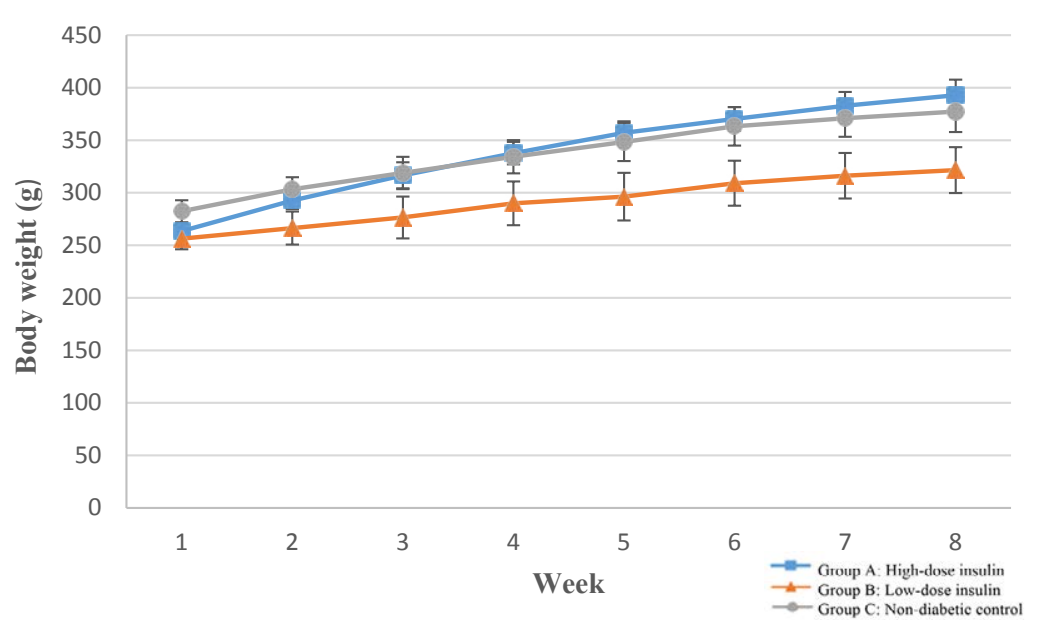

Figure 1: Mean body weight $( \pm$ SEM) (g) of the rats in Groups A, B and C throughout the eight-week treatment.

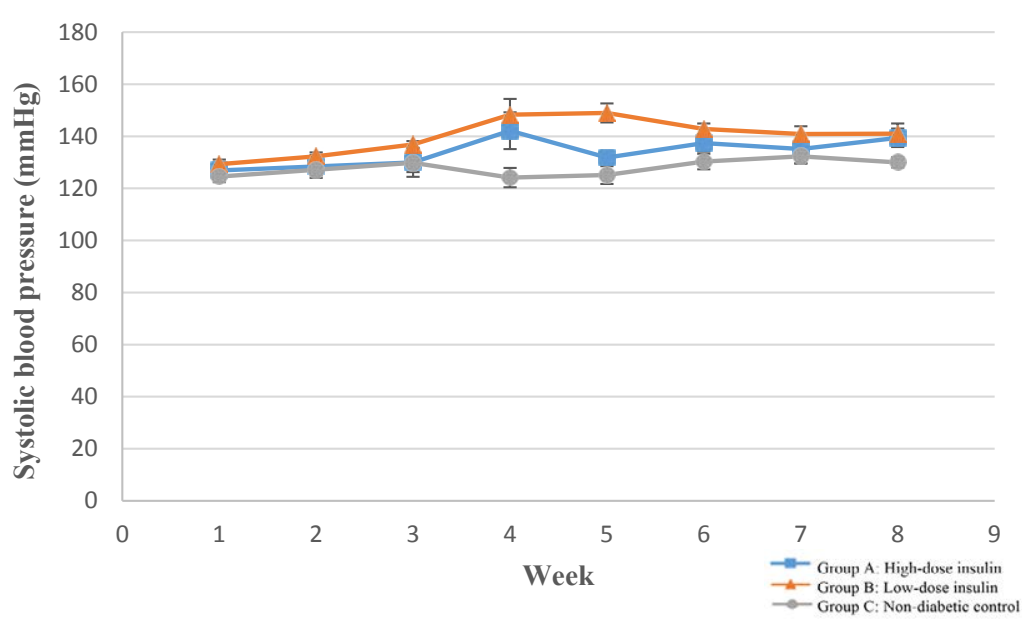

Figure 2: Mean systolic blood pressure $( \pm$ SEM) $(\mathrm{mmHg})$ of the rats in Groups $A, B$ and $C$ throughout the eight-week treatment. 


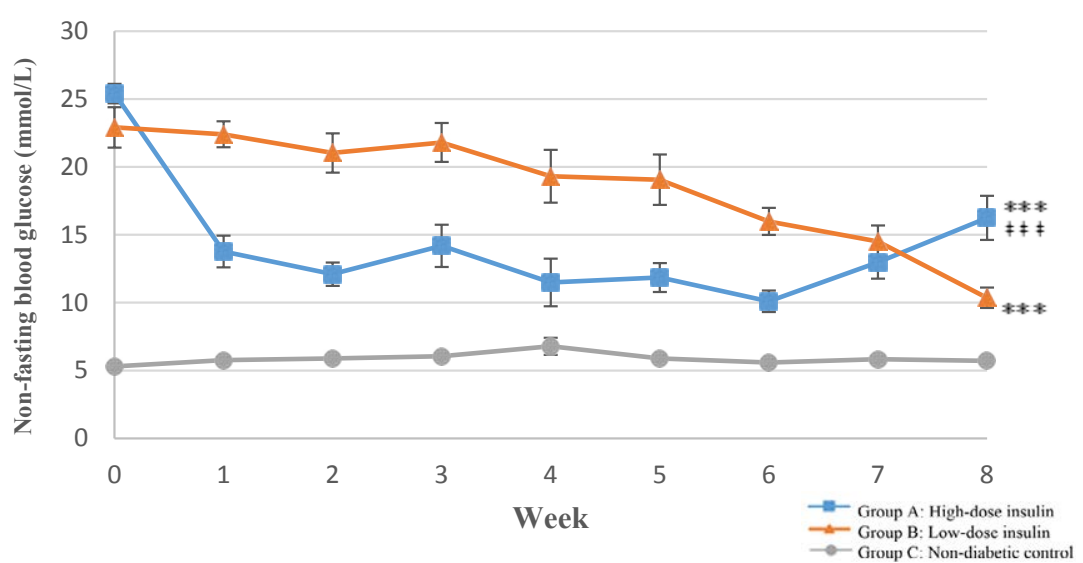

Figure 3: Mean non-fasting blood glucose concentration $( \pm S E M)(m m o l / L)$ of the rats in Groups $A, B$ and $C$ throughout the eight-week treatment. $\neq \neq \neq$ significant compared to Group B $(p \leq 0.001) ;{ }^{* *+}$ significant compared to Group C $(p \leq 0.001)$.

\begin{tabular}{|c|c|c|c|}
\hline \multirow{2}{*}{ Biochemical analyses } & $\begin{array}{c}\text { Group A } \\
\text { Diabetic rats given high dose insulin } \\
\mathbf{( 5 - 7 U ~ p e r ~ d a y ) ~}\end{array}$ & $\begin{array}{c}\text { Group C } \\
\mathbf{n = 7}\end{array}$ & $\begin{array}{c}\text { Group B } \\
\text { Diabetic rats given low dose insulin } \\
\mathbf{( 0 - 3 U} \text { per day) }\end{array}$ \\
\cline { 2 - 4 } & $14.16 \pm 2.11^{* \neq}$ & $\mathbf{n = 7}$ \\
\hline Fasting blood glucose $(\mathrm{mmol} / \mathrm{L})$ & $4.07 \pm 0.35$ & $6.6 \pm 1.05$ \\
\hline $\mathrm{HbA1c}(\mu \mathrm{g} / \mathrm{mL})$ & $13.89 \pm 4.63^{* \neq}$ & $3.18 \pm 0.19^{*}$ \\
\hline NF-KB $(\mathrm{pg} / \mathrm{mL})$ & $282.74 \pm 28.46$ & $40.55 \pm 1.50$ \\
\hline
\end{tabular}

Data are means \pm SEM. * significant compared to $C(p \leq 0.05)$; ₹ significant compared to $B(p \leq 0.05)$.

HbA1c: glycated haemoglobin; NF-kB: nuclear factor kappa B; AGE: advanced glycation end product.

Table 2: Blood and serum biochemical parameters for rats in Groups A, B and C measured at the end of eight-week treatment.

$(p \leq 0.05)$ whereas the mean NF- $\kappa B$ concentration of the rats in Group A was significantly lower than both Groups B and C $(\mathrm{p} \leq 0.05)$ (Table 2).

There was no significant difference in the mean serum AGE concentration between all the groups despite the differences in blood glucose level ( $\mathrm{p}>0.05)$ (Table 2). In a short term period, insulin treatments given to the diabetic rats had countered the expected accumulation of AGE. Using Group A as the calibrator in the experiment, the RAGE expression ( \pm SEM) of Group B was upregulated in the abdominal muscle (AM), subcutaneous (SAT) and visceral adipose tissue (VAT) by $1.10 \pm 1.20$ fold, $2.70 \pm 3.78$ fold and $1.02 \pm 1.29$ fold respectively, but was down-regulated in the liver (L), and kidney $(\mathrm{K})$ by $2.13 \pm 2.79$ fold and $1.45 \pm 0.74$ fold respectively. Nevertheless, the changes in RAGE expression in all these tissues was not statistically significant $(\mathrm{p}>0.05)$. Only in the heart $(\mathrm{H})$ tissue, the RAGE expression significantly down-regulated by $2.04 \pm 1.17$ fold ( $\mathrm{p} \leq 0.05)$ (Figure $4 \mathrm{~A}$ ). On the other hand, the relative expression of RAGE for Group B (target) to Group C (calibrator) as well as Group A (target) to Group C (calibrator) showed no significant up-regulation and down-regulation ( $p>0.05$ ) (Figure $4 B$ and $4 C$ ).

\section{Discussion}

\section{Chronic hyperglycemia hinders normal growth by reducing weight gain}

Body weight is one of the parameters to be considered in the development and growth of the laboratory rat model [12]. During the first five weeks of treatment, rats in Group B had high blood glucose concentrations but were given only low-dose insulin. The insulin dosage given was not sufficient to reduce the blood glucose to physiological relevant level. This condition of chronic hyperglycemia had significantly reduced the total weight gain of the rats. Insulin plays an important role in anabolic processes and the loss of its effects is the main cause for weight reduction observed in diabetic patients $[13,14]$. The liver, muscle and adipose tissues are insulin responsive tissues. They respond differently to insulin action. Firstly, insulin stimulates glucose uptake for glycogen synthesis in the liver by activating glycogen synthase. On the other hand, insulin increases the uptake of glucose into muscles and adipose tissues by inducing the translocation of glucose transporter 4 (GLUT-4) to cell surface [15]. Excess glucose will be stored as glycogen in the muscle. Meanwhile, glucose will be converted to fatty acids and stored as triglyceride in adipose tissues. Besides glucose, insulin also promotes the uptake of amino acids and free fatty acid into the muscle and adipose tissues respectively [15]. When there is insufficient insulin, the tissues is unable to take up glucose and utilize it for energy production. Prolonged energy starvation will stimulate proteolysis in the muscle and lipolysis in adipose tissues [16]. Both muscles breakdown and depletion of triglyceride stores contribute to weight loss [17]. Hence, the weight gain across time for rats in Group B is significantly lesser than rats in Groups A and C.

\section{Chronic hyperglycemia induces high blood pressure}

Increased blood glucose level accelerates the early glycation process, increasing the formation of a-oxoaldehydes such as glyoxal, methyglyoxal and 3-deoxyglucosone [18]. These reactive glucose metabolites are the precursors for the formation of advanced glycation end products (AGEs) and are thought to activate the renin-angiotensin system (RAS) thereby elevating systolic blood pressure.

RAS activation is initiated by the secretion of renin from the kidney. As the rate-limiting enzyme, renin catalyzes the conversion 

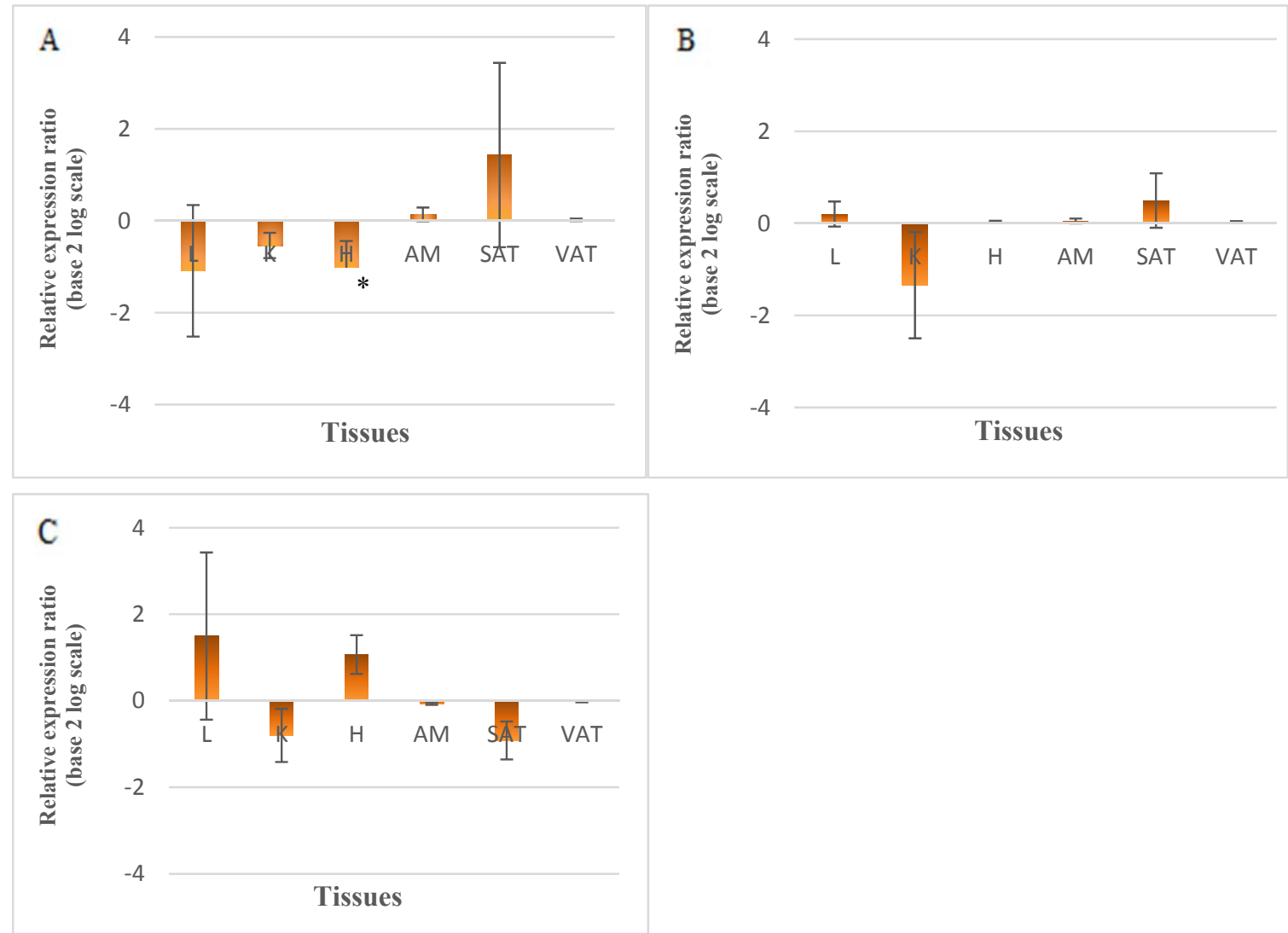

Figure 4: Relative expression ratios ( \pm SEM) of RAGE of $(A)$ Group $B$ to $A(B)$ Group $B$ to $C(C)$ Group $A$ to $C$ in base log 2 scale for different tissues with $B A C$ as the reference gene. The positive values imply up-regulation and negative values imply down-regulation. ( ${ }^{*}$ indicates $p \leq 0.05$ when compared between groups) $\mathrm{L}$ : liver; $\mathrm{K}$ : kidney; $\mathrm{H}$ : heart; AM: abdominal muscle; SAT: subcutaneous adipose tissue; VAT: visceral adipose tissue.

of angiotensinogen to angiotensin I (AngI). Angiotensin I is further hydrolyzed to angiotensin II (AngII) by angiotensin-converting enzyme (ACE). Angiotensin II actively stimulates the sympathetic activity, increases sodium reabsorption, promotes arteriole vasoconstriction and increases anti-diuretic hormone. All these activities raise the systolic blood pressure [19,20]. Dhar et al. [21] showed that excessive methyglyoxal production activated the transcription factor nuclear factor kappa $\mathrm{B}(\mathrm{NF}-\mathrm{\kappa} \mathrm{B})$ via a receptor for advanced glycation end products (RAGE) with subsequent activation of RAS.

Apart from the RAS, activation of the protein kinase C (PKC) is also contributing to the systolic blood pressure elevation. Increased generation of the second messenger diacylglycerol (DAG) during hyperglycemia activates $\mathrm{PKC}$. Activated $\mathrm{PKC}$ suppresses the production of endothelial nitric oxide (NO) and reduces $\mathrm{NO}$-mediated vasodilation in microvasculature [22-25]. In type 1 diabetes, development of diabetic nephropathy is often the major cause of hypertension [26]. Activation of PKC- $\beta$ isoforms was observed in the renal glomeruli of diabetic rats and the use of specific PKC- $\beta$ inhibitor improved the glomerular filtration rate and albumin excretion rate [27-29]. Since the use of PKC inhibitor had been shown to restore vascular function, the systolic blood pressure can be lowered following the occurrence of vasodilation [30]. This is observed towards the end of our study when rats in Group $\mathrm{B}$ had lowered systolic blood pressure as a result of improved glucose metabolism. The rats in Group A were given higher insulin dosage to lower the blood glucose to near normal level. A better glycemic control with the use of high-dose insulin reduced the activation of RAS and
PKC [27,31]. Therefore, there was no significant difference in the systolic blood pressure between Group C (non-diabetic control) and Group A.

\section{Low-dose insulin treatment reduces glucose level whereas high-dose insulin treatment is deduced to cause insulin resistance}

Our results suggest that low-dose insulin treatment helped to reduce the mean fasting blood glucose concentration to normal level. Meanwhile, high-dose insulin treatment increased the fasting blood glucose concentration of rats. The high-dose insulin treatment given is speculated to promote insulin resistance. A short term hyperinsulinization promotes the translocation of glucose transporter to the plasma membrane of adipose tissue thereby enhancing the insulin-stimulated glucose uptake [32]. However, long term exposure to high concentration of insulin may suppress the glucose transporter 4 (GLUT-4) gene expression [33]. The development of insulin resistance in hyperinsulinized subjects may cause disruption at different branch points of the insulin-mediated phosphatidylinositol 3-kinase/ protein kinase B (PI-3kinase/Akt) pathway [34]. These include reduction in tyrosine autophosphorylation of insulin receptor (IR), phosphorylation of glycogen synthase kinase (GSK-3), translocation of GLUT-4 to the plasma membrane of muscle tissue as well as deregulated FOXO1 transcription factor $[34,35]$. This may explain the reason for the high fasting blood glucose recorded in Group A rats treated with high-dose insulin. 
HbA1c value weighted proportionally towards recent glycation levels reflecting value similar to fasting blood glucose

Theoretically, HbAlc and mean plasma glucose should demonstrate a linear relationship by providing an average blood glucose for the preceding two to three months. By analysing the trend, our HbAlc results seem to reflect the fasting blood glucose results obtained at the end of the experiment. Studies on the kinetic between glucose and haemoglobin with consideration of the age of $\mathrm{RBC}$ and glucose concentration, revealed that $\mathrm{HbAlc}$ level will weigh heavily towards recent glycation levels rather than presenting the exact average blood glucose for the past three months [36]. This means that $50 \%$ of the glycation will occur in the current month (phase 3 ) prior to the test and the month before (phase 2) accounts for another $25 \%$. The remaining $25 \%$ is formed in the earlier stage (phase 1 ) when the $\mathrm{RBC}$ is newly produced [37]. Although the rats in Group B had poor blood glucose control during the first five weeks of treatment, their HbAlc levels were the lowest among all the groups. Since HbAlc is a reversible glycated product, enzymatic deglycation catalyzed by fructosamine-3-kinase (FN3K) can reverse the glycation of glucose to haemoglobin [38]. The enzymatic deglycation is a defense mechanism to safeguard against cellular damage caused by the glycated product. However, the enzymatic deglycation mechanism is challenged by extreme hyperglycemia [38]. Our treatment period might be too short that the enzymatic deglycating system is still able to reverse the glycation of haemoglobin [38]. Diabetic rats from both the Groups $\mathrm{A}$ and $\mathrm{B}$ had lower HbAlc level than non-diabetic rats from Group C. This may due to the effects of insulin as insulin has shown to alter the ionic composition of RBC [39]. This possibly affects the glycation process. Apart from that, the blood glucose level in Groups A and B fluctuated from day to day compared to Group $C$ in which the rats had stable blood glucose level throughout the study. Thus, the observed significantly higher $\mathrm{HbAlc}$ value in Group $\mathrm{C}$ might be due to the glycemic instability in both Groups A and B [40].

Multiple insulin injections given in high-dose insulin treatment reduce excessive fluctuation of blood glucose thereby preventing sustained activation of NF- $\mathrm{kB}$

Multiple insulin injections per day received by rats in Group A had shown to prevent excessive fluctuation of blood glucose thereby preventing the sustained activation of NF- $\kappa B$. A constant high glucose level promotes intracellular glucose oxidation. In this metabolic pathway, the increased production of reactive oxygen species (ROS) as induced by high glucose initiates the synthesis of diacylglycerol (DAG) from phosphatidylcholine (PC). High DAG level further increases the activation of protein kinase $\mathrm{C}$ (PKC) followed by the activation of NF- $\mathrm{KB}$ [41]. Aside from the activation of PKC, oxidative stress stimulation is another route for NF- $\kappa B$ activation [42]. In spite of the negative impact, NF- $\kappa \mathrm{B}$ activation is essential as part of the positive regulatory circuit for glucose-stimulated insulin secretion (GSIS) [43]. Calcium influx in GSIS has been shown to trigger the activation of NF- $\kappa B$ via mitogenactivated protein (MAP)/ERK (extracellular signalrelated kinase) (MEK)/MAP kinase (MAPK) to ensure high GLUT-2 expression. Suppressed NF- $\mathrm{KB}$ is shown to impair GSIS [43]. This may explain the NF- $\mathrm{KB}$ activation observed in the control group.

\section{Short term glucose overload and exogenous insulin decrease} the rate of AGE accumulation

Methyglyoxal (MG) is an intermediate metabolite in the AGEs formation pathway. Increased rate of MG accumulation as a consequence of high glucose level, leads to a build-up of dicarbonyl stress. Dicarbonyl stress build-up during the non-enzymatic glycation might have induced over-expression of the glyoxalase system, which is comprised of enzymes responsible for the degradation of MG [44]. Hence, with less amount of MG, subsequent formation of AGE will be reduced as well. Increased expression of glyoxalase 1 enzyme (Glo1) inhibits posttranslational modification of proteins by MG thereby preventing the formation of AGEs and other stable glycated products [44]. Apart from this, increased exposure to insulin can promote elimination of AGEs. Insulin acts via the PI-3K signalling pathway to regulate macrophage scavenger receptor (MSR)-mediated endocytic uptake and degradation of AGEs [45]. However, the exact mechanism of this still remains unclear and needs to be explored further. The expected increase in serum AGE level in Groups A and B might be offset due to the effects of exogenous insulin.

\section{RAGE gene in rats undergoes various alternative splicing and other RAGE isoforms may be prevalent in diabetic state}

RAGE protein can exist in different isoforms as a result of alternative splicing of the RAGE gene [46]. The splice variants produced may have different amino acid sequences that give distinct ligand binding domain and possibly with transmembrane region excluded, generating nonmembrane-bound receptors in secreted form [46]. In murine model, various splice variants had been identified to be uniquely distributed in different tissues. Kalea et al. [47] comparing the changes in splice variant for age-matched diabetic and non-diabetic mice showed that the production of the soluble RAGE (sRAGE) splice variants increased in diabetic condition compared to normal physiological condition. This may explain the non-significant changes in RAGE expression on tissues studied because the RAGE protein could be expressed in other isoforms such as sRAGE. In addition to that, AGE-mediated up-regulation of RAGE expression is dependent on the exposure duration and concentration of AGE [48]. Since there was no significant difference in AGE level among the groups in the present study, AGEmediated increase in RAGE expression was not significant as well. A longer duration would be needed to investigate whether significant AGE accumulation could be detected in the diabetic rats from Groups $\mathrm{A}$ and $\mathrm{B}$.

By comparing the relative expression ratio of Group B to Group $A$, there is a significant down-regulation of RAGE gene in the heart tissue. Besides binding to pathological ligand (AGE), RAGE binds to physiological ligands such as amphoterin (HMGB1) and S100/ calgranulins [49]. Cellular stress caused by glucose overload may stimulate the production of these pro-inflammatory ligands thereby up-regulating the expression of RAGE [50]. Improved glucose metabolism as shown in Group B rats that were given low-dose insulin treatment had a comparably lower RAGE gene expression than Group A rats. This may be possibly due to minimal production of the proinflammatory ligands.

\section{Conclusion}

In conclusion, low-dose insulin treatment was shown to be a better therapeutic intervention for type 1 diabetes as compared to high-dose insulin treatment. Our study suggested that low-dose insulin improved glucose metabolism in diabetic rats. Future work can focus on the underlying mechanism of the hormone action and metabolism.

\section{Acknowledgements}

This study was funded by Monash University Malaysia School of Science and Ministry of Science, Technology and Innovation (02-02-10-SF0249). We would 
like to acknowledge Mr Andrew Leong Kum Loong, Mr Zulkhaili Zainal and Ms Tiang Ning for their technical support in animal handling as well as Mr Cheng Hong Sheng for his advice.

\section{References}

1. Whiting DR, Guariguata L, Weil C, Shaw J (2011) IDF Diabetes Atlas: Global estimates of the prevalence for 2011 and 2030. Diabetes Res Clin Prac 94: 311-321.

2. World Health Organization (2012) The top 10 causes of death by country income group. WHO Press.

3. Ministry of Health. Diabetic epidemic in Malaysia (2013) National Strategic Plan for Non-Communicable Disease.

4. Loghmani E (2005) Diabetes mellitus: type 1 and type 2. In guidelines for adolescent nutrition services, Edited by Stang \& Story, Minneapolis, Center for Leadership. Education and Training in Maternal and Child Nutrition 167-182.

5. Ryden L, Standl E, Bartnik M, Berghe, G, Betteridge, J, et al. (2007) Guideline on diabetes, pre-diabetes, and cardiovascular diseases. Eur Heart J 9: C3-C74.

6. Luevano-Contreras C, Chapman-Novakofski K (2010) Dietary advanced glycation end products and aging. Nutrients 2: 1247-1265.

7. Brownlee M (2001) Biochemistry and molecular cell biology of diabetic complications. Nature 414: 813-820.

8. Piarulli F, Sartore G, Lapolla A (2013) Glyco-oxidation and cardivascular complications in type-2 diabetes: a clinical update. Acta Diabetol 50: 101-110.

9. Goldin A, Beckman JA, Schmidt AM, Creager, MA (2006) Advanced glycation end products: Sparking the development of diabetic vascular injury. Circulation 114: 597-605.

10. Qin J, Goswami R, Dawson S, Dawson G (2008) Expression of the receptor for advanced glycation end products in oligodendrocytes in response to oxidative stress. J Neurosci Res 86: 2414-2422.

11. Basta G, Schmidt AM (2004) Advanced glycation end products and vascular inflammation: implications for accelerated atherosclerosis in diabetes. Cardiovasc Res 63: 582-592.

12. Sengupta $P$ (2011) A scientific review of age determination for a laboratory rat: How old is it in comparison with human age? Biomedicine International 2 81-89.

13. King AJF (2012) The use of animal models in diabetes research. Br J Pharmaco 166: 877-894.

14. Novikova L, Smirnova IV, Rawal S, Dotson AL, Benedict SH, et al. (2013) Variations in rodent models of type 1 diabetes: Islet morphology. J Diabetes Res: 965832.

15. Nussey S, Whitehead S (2001) Endocrinology: An integrated approach. BIOS Scientific Publishers Chapter 2: 23-68.

16. Finn PF, Dice JF (2006) Proteolytic and lipolytic responses to starvation Nutrition 22: 830-844.

17. Eiselein L, Schwartz HJ, Rutledge JC (2004) The challenge of type 1 diabetes mellitus. ILAR J 45: 231-236.

18. Thornalley PJ, Langborg A, Minhas, HS (1999) Formation of glyoxal, methyglyoxal and 3-deoxyglucosone in the glycation of proteins by glucose. Biochem J 344: 109-116.

19. Atlas SA (2007) The renin-angiotensin aldosterone system: pathophysiological role and pharmacologic inhibition. J Manag Care Spec Pharm 13: 9-20.

20. Pacurari M, Kafoury R, Tchounwou PB, Ndebele K (2014) The renninangiotensin-aldosterone system in vascular inflammation and remodelling. Int J Inflam: 689360.

21. Dhar I, Dhar A, Wu L, Desai KM (2014) Methyglyoxal, a reactive glucose metabolite, increases rennin angiotensin aldosterone and blood pressure in male Sprague-Dawley rats. Am J Hypertens 27: 308-316.

22. Craven PA, Studer RK, DeRubertis FR (1994) Impaired nitric oxide-dependent cyclic guonosine monophosphate generation in glomeruli from diabetic rats. Evidence for protein kinase C-mediated suppression of the cholinergic response. J Clin Invest 93: 311-320.

23. Ganz MB, Seftel A (2000) Glucose-induced changes in protein kinase $C$ and nitric oxide are prevented by vitamin E. Am J Physiol Endocrinol Metab 278: E146-152.
24. Kuboki K, Jiang ZY, Takahara N, Ha SW, Igarashi M, et al. (2000) Regulation of endothelial constitutive nitric oxide synthas gene expression in endothelia cells and in vivo: a specific vascular action of insulin. Circulation 101: 676-681.

25. Paniagua OA, Bryant MB, Panza JA (2001) Role of endothelial nitric oxide in shear stress-induced vasodilation of human microvasculature: diminished activity in hypertensive and hypercholesterolmic patients. Circulation 103 1752-1758.

26. Lago RM, Singh PP, Nesto RW (2007) Diabetes and hypertension. Nat Clin Pract Endocrinol Metab 3: 667.

27. Craven PA, DeRubertis FR (1989) Protein kinase C is activated in glomerul from sreptozotocin diabetic rats. Possible mediation by glucose. J Clin Invest 83: 1667-1675.

28. Ishii H, Jirousek MR, Koya D, Takagi C, Xia P, et al. (1996) Amelioration of vascular dysfunctions in diabetic rats by an oral PKC beta inhibitor. Science 272: 728-731.

29. Koya D, Lee IK, Ishii H, Kanoh H, King GL (1997) Prevention of glomerular dysfunction in diabetic rats by treatment with d-alpha tocopherol. Clin J Am Soc Nephrol 8: 426-435.

30. Lu X, Bean JS, Kassab GS, Rekhter MD (2011) Protein kinase C inhibition ameliorates functional endothelial insulin resistance and vascular smooth muscle cell hypersensitivity to insulin in diabetic hypertensive rats. Cardiovasc Diabetol 10: 48

31. Scholey JW, Meyer TW (1989) Control of glomerular hypertension by insulin administration in diabetic rats. J Clin Invest 83: 1384-1389.

32. Cushman SW, Wardzala LJ (1980) Potential mechanism of insulin action on glucose transporter in the isolated rat adipose cell. Apparent translocation of intracellular transport systems to the plasma membrane. J Biol Chem 255 4758-4762.

33. Flores-Riveros JR, McLenithan JC, Ezaki O, Lane MD (1993) Insulin downregulates expression of the insulin-responsive glucose transporter (GLUT4) gene: effects on transcription and mRNA turnover. Proc Natl Acad Sci USA 90: $512-516$

34. Okamoto MM, Anhe GF, Sabino-Silva R, Marques MF, Freitas HS, et al. (2011) Intensive insulin treatment induces insulin resistance in diabetic rats by impairing glucose metabolism-related mechanisms in muscle and liver. $J$ Endocrinol 211: 55-64.

35. Gonzalez E, Flier E, Molle D, Accili D, McGraw TE (2011) Hyperinsulinemia leads to uncoupled insulin regulation of the GLUT4 glucose transporter and the FoxO1 transcription factor. Proc Natl Acad Sci USA 108: 10162-10167.

36. Tahara Y, Shima K (1995) Kinetics of HbA1c, glycated albumin, and fructosamine and analysis of their weight functions against preceding plasma glucose level. Diabetes Care 18: 440-447.

37. Makris K, Spanou L (2011) Is there a relationship between mean blood glucose and glycated haemoglobin. J Diabetes Sci Technol 5: 1572-1583.

38. Szwergold BS, Howell S, Beisswenger PJ (2002) Nonenzymatic glycation/ enzymatic delycation: a novel hypothesis on the etiology of diabetic complications. Int Congr Ser 1245: 143-152.

39. Houston $\mathrm{AH}$ (1988) Insulin affects ionic composition of rainbow trout erythrocytes. Regul Pept 22: 199-204

40. Kilpatrick E (2000) Glycated haemoglobin in the year 2000. J Clin Pathol 53 335-339.

41. Nishikawa T, Edelstein D, Du XL, Yamagishi S, Matsumura T, et al. (2000) Normalizing mitochondrial superoxide production blocks three pathways of hyperglycaemic damage. Nature 404: 787-790.

42. Romeo G, Liu WH, Asnaghi V, Kern TS, Lorenzi M (2002) Activation of nuclea factor-kappaB induced by diabetes and high glucose regulates a proapoptotic program in retinal pericytes. Diabetes 51: 2241-2248.

43. Norlin S, Ahlqren U, Edlund $\mathrm{H}$ (2005) Nuclear factor-\{kappa\}B activity in \{beta\}cells is required for glucose-stimulated insulin secretion. Diabetes 54: 125-132.

44. Giacco F, Du X, D'Agati VD, Milne R, Sui G, et al. (2014) Knockdown of glyoxalase 1 mimics diabetic nephropathy in nondiabetic mice. Diabetes 63 291-299.

45. Sano H, Higashi T, Matsumoto K, Melkko J, Jinnouchi Y, et al. (1998) Insulin enhances macrophage scavenger receptor-mediated endocytic uptake of advanced glycation end products. J Biol Chem 273: 8630-8637. 
Citation: Ng AXH, Ton SH, Kadir KA (2016) Low-dose Insulin Treatment Ameliorate Glucose Metabolism in Type 1 Diabetic Rats. J Diabetes Metab 7: 635. doi:10.4172/2155-6156.1000635

Page 8 of 8

46. Hudson BI, Carter AM, Harja E, Kalea AZ, Arriero M, et al. (2008) Identification, classification, and expression of RAGE gene splice variants. FASEB J 22 1572-1580.

47. Kalea AZ, Reiniger N, Yang H, Arriero M, Schmidt AM, et al. (2009) Alternative splicing of the murine receptor for advanced glycation end-products (RAGE) gene. FASEB J 23: 1766-1774.

48. Yu L, Zhao Y, Xu S, Ding F, Jin C, et al. (2013) Advanced glycation end product
(AGE)-AGE receptor (RAGE) system upregulated connexin43 expression in rat cardiomyocytes via PKC and Erk MAPK pathways. Int J Mol Sci 14: 2242-2257.

49. Yao D, Brownlee M (2010) Hyperglycemia-induced reactive oxygen species increase expression of the receptor for advanced glycation end products (RAGE) and RAGE ligands. Diabetes 59: 249-255.

50. Yan SF, Ramasamy R, Schmidt AM (2009) Receptor for AGE (RAGE) and its ligands-cast into leading roles in diabetes and the inflammatory response. $J$ Mol Med 87: 235-247. 